\title{
THE INFLUENCE OF THE FLUSHING METHOD ON THE STABLE OXYGEN CONTENT IN THE SCR 1 CRABE BREATHING LOOP IN THE DECOMPRESSION PHASE
}

Arkadiusz Woźniak

Department of Underwater Works Technology of the Polish Naval Academy, Gdynia, Poland

\section{ABSTRACT}

Maintaining a stable oxygen content in the breathing loop of the diving apparatus with a semi-closed respiratory circuit is essential for the safety of underwater mine clearance operations. This article discusses the influence of modified methods of flushing the breathing apparatus on the quality of the breathing loop ventilation process. The problem of flushing an apparatus is presented in light of the Polish Naval Academy's change from statistical to deterministic decompression schedules, based on the model of apparatus ventilation, oxygen toxicity hazard and decompression. The examination and determination utilising the required accuracy of the method used for flushing the breathing loop of the device allowed to assess the stable oxygen content during the decompression phase. The assumptions were verified based on a system for measuring oxygen content in the breathing loop.

Keywords: diving apparatus, breathing gas for hyperbaric purposes, flushing process, diving technology.

\section{ARTICLE INFO}

PolHypRes 2020 Vol. 70 Issue 1 pp. 21 - 42

ISSN: 1734-7009 elSSN: 2084-0535

DOI: $10.2478 / \mathrm{phr}-2020-0002$

Pages: 22, figures: 16 , tables: 4

page www of the periodical: www.phr.net.pl

Publisher

Polish Hyperbaric Medicine and Technology Society

\section{Original article}

Submission date: $14.12 .2019 \mathrm{r}$.

Acceptance for print: 25.01.2020 r. 


\section{INTRODUCTION}

The withdrawal of FGT I/D2 diving devices from the Armed Forces of the Republic of Poland (SZRP) made it necessary to introduce [1] ${ }^{3}$ into use ${ }^{4}$ SZRP and NAT05,6 compliant [2,3] SCR CRABE semi-closed rebreathers[4]. The acquired diving technology necessitated validation ${ }^{7}$ taking into account national circumstances and the needs of the Navy of the Republic of Poland with regard to the performance of $\mathrm{MCM}^{8}$ and EOD ${ }^{9}$ operations. Scientific verification of the adopted assumptions, development of the ventilation model and decompression schedules due to obligatory reasons ${ }^{10}$ required the $N C B i R^{11}$ to commission scientific and research work. Validation of the new technology of performing underwater mine clearance operations ${ }^{12}$ [9] and $E O D$ with the use of SCR CRABE was entrusted to ZTTP AMW under the contract DOBR/0047/R/ID1/2012/03 "Decompression design for MCM dives"13.

As part of the above mentioned project task, diving technologies with the use of $N x 32.5 \% 02$ nitrox mixes in the depth range of $45-60 \mathrm{~m} \mathrm{H}_{2} \mathrm{O}^{14}$ with the use of oxygen and nitrox decompression were developed at the result level. The study design that has been approved for implementation now continues as part of research work: Tulipan IV agreement No.: DOBR-BI08/09/01/2016, entitled: "Designing decompression for $M C M / E O D I I$ diving". The main objective is to develop nitrox diving technology at the validation level in the range of $0-60 \mathrm{mH} 20$ corresponding to the system II according to NO - 07-A010:2010 [6]. Developing homebred technology will facilitate a breakthrough of existing barriers and limitations in the use of the SCR CRABE 15 apparatus [10] and significantly increase the operational capacity of the Polisharmed forces [5] in the implementation of $M C M$ tasks.

\section{Problem SITUATION}

As part of the research on the development of diving technology, a number of works have been carried out in order to establish a methodology for diving apparatus ventilation. As shown by the analysis of the context ${ }^{16}$ related to the process of designing decompression for the SCR CRABE apparatus, actions had to be taken to establish an effective method of flushing the breathing loop of the apparatus. In the course of experimental dives using the breathing loop of the apparatus, changes in oxygen ${ }^{17}$ content in relation to the established tolerance ${ }^{18}$ limits were observed. The observation of the changes that were taking place in the minimum stable oxygen content was made for premix nitrox mixtures of $\mathrm{Nx} 60.0 \% \mathrm{v} \frac{\mathrm{O}_{2}}{\mathrm{~N}_{2}}, \mathrm{Nx} 40.0 \% \mathrm{v} \frac{\mathrm{O}_{2}}{\mathrm{~N}_{2}}$ and $\mathrm{Nx} 32.5 \% \mathrm{vO}_{2} / \mathrm{N}_{2}$. Research was carried out in to the process of flushing the apparatus with $\mathrm{O}_{2}$ in the decompression phase carried out in water from a depth of $15 \mathrm{~m} \mathrm{H}_{2} \mathrm{O}$. As it is known, apparatus with a semi-closed respiratory circuit features a relative decrease in the content of $\mathrm{O}_{2}$ to a stable value in the breathing loop relative to the original oxygen content in the premix. This phenomenon is caused by mixing the regenerated respiratory gas with fresh premix ${ }^{19}$.

The SCR CRABE ventilation model developed in the course of separate studies shows that stable partial pressure in the breathing loop of the diving apparatus depends, among other things, on the diving depth, while the process of flushing the breathing loop of the apparatus is equally effective at any depth [8]. During the dive, depending on the type of premix applied, partial pressure should not change below the established physiological limit and should not exceed the established limits known to increase the possibility of central nervous oxygen toxicity 20 .

\section{THE AIM OF THE STUDY}

The decompression system developed under the project consists of the following tables:

- A table of basic $N x / O_{2}$ and accelerated $N x$ and $\mathrm{Nx} / \mathrm{O}_{2}$ decompression for the $\mathrm{Nx} / \mathrm{O}_{2}-$ SCR CRABESCUBA apparatus powered by $N x: 32,5_{-0,5}^{+0} \%{ }_{v} O_{2}$ in the depth range of $[27 \div 60] \mathrm{mH}_{2} \mathrm{O}$.

- A table of basic decompression $N x / \mathrm{O}_{2}: \mathrm{Nx}$ and $\mathrm{Nx} / \mathrm{O}_{2}$ for the $\mathrm{Nx} / \mathrm{O}_{2}-S C R$ CRABE SCUBA apparatus powered by $N x: 40,0_{-0,5}^{+0} \%_{v} O_{2}$ in the depth range of $[24 \div 48] \mathrm{mH}_{2} \mathrm{O}$.

- A table of direct decompression $\mathrm{Nx} / \mathrm{O}_{2}$ for the $\mathrm{Nx} / \mathrm{O}_{2}-\mathrm{SCR} C \mathrm{RABESCUBA}$ apparatus powered by $N x: 60,0_{-0,5}^{+0} \%{ }_{v} O_{2}$ in the depth range of $[0 \div 24) \mathrm{mH}_{2} \mathrm{O}$.

At a certain stage of design research, the knowledge base made it possible to separate the ventilation model, decompression planning of the analysed system and the processes taking place in it. The establishment of models made it possible to change the statistical approach to a partially deterministic one, and the basis for the development of decompression schedules was the establishment of a model of a breathing, ventilation, decompression and oxygen toxicity hazard module, Fig. 1 [11] 


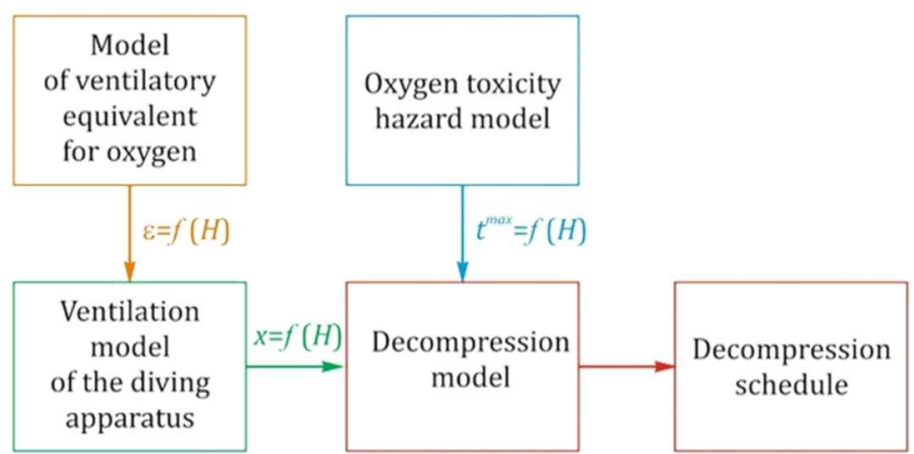

Fig. 1 Model succession. Source: study based on: R. Kłos. Modeling of the diving systems with semi-closed circuit of the breathing agent. UDWG 2015.

Due to changes in the composition of the breathing gas inhaled by the diver during the decompression phase depending, among other things, on the diving apparatus design parameters, a sub-process of flushing the apparatus with $\mathrm{O}_{2}$ was singled out from the model of ventilation in the decompression phase. This process, due to its course in the systemic environment, which is the context for the analysis of the sub-processes taking place in them, was analysed with regard to the systemic approach. The process was indirectly connected with the ventilation model as a system element. The main objective was to develop an effective procedure for oxygen flushing of the breathing loop of the SCR CRABE apparatus within the adopted decompression schedules for nitrox diving within the range of $0-60 \mathrm{mH}_{2} \mathrm{O}$.
Fig. 2 demonstrates a schematic analysis of the breathing system of the device (bag-in-bag design), together with the direction of gas flow during inhalation and exhalation, which is the basis for the analysis of process changes occurring during the flushing of the premix ${ }^{21}$ out of the breathing loop with oxygen during the decompression phase. Flushing was performed based on the implementation of modified ${ }^{22}$ variants of the oxygen flushing procedure. The modification of the sub-process was designed to move towards obtaining a stable value of oxygen partial pressure $p_{\mathrm{O}_{2}}$ in relation to a defined critical value.

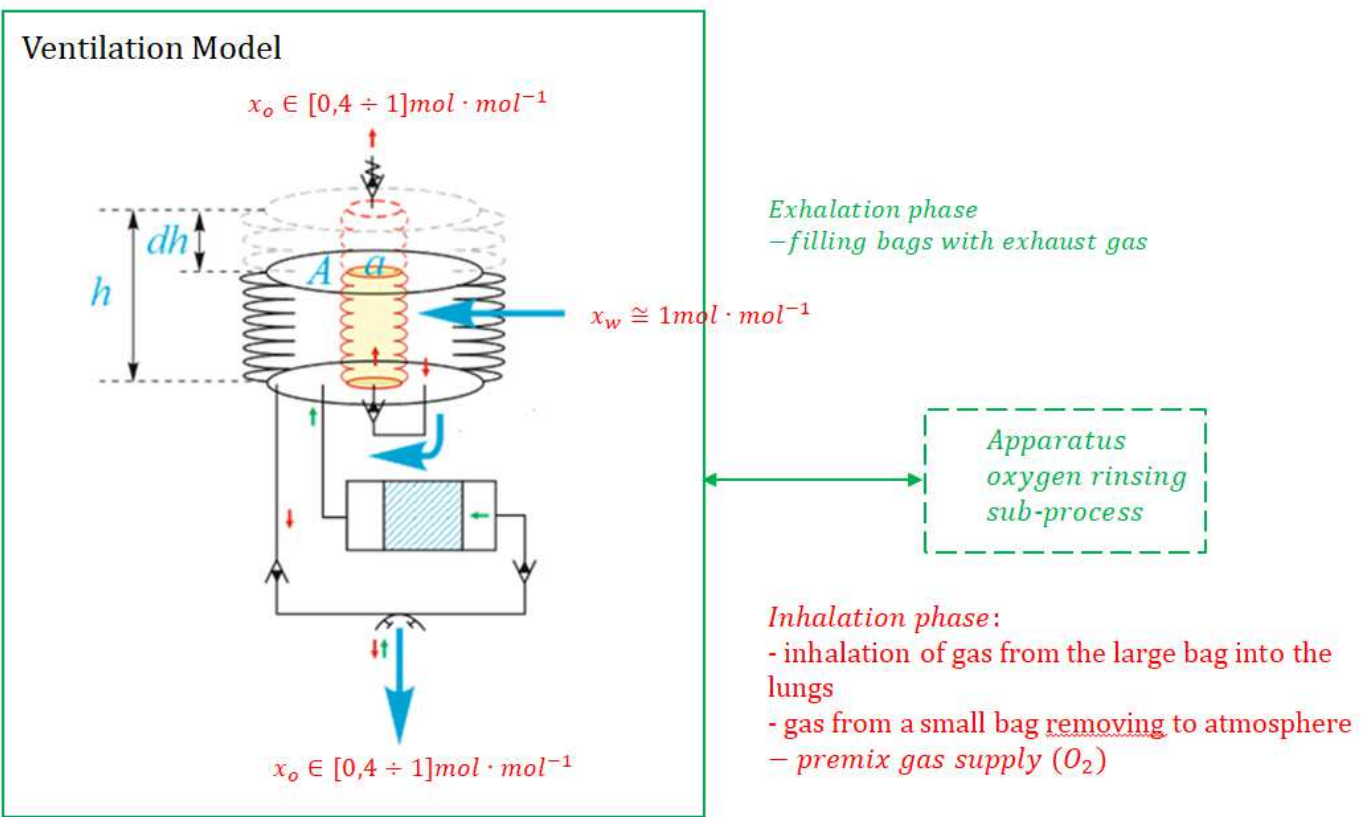

Fig. 2 Breathing system of a SCR CRABE diving apparatus with a semi-closed respiratory circuit. Source: based on: R. Kłos. Modeling of the diving systems with semi-closed circuit of the breathing agent. UDWG 2015. 
When flushing the diving apparatus, the oxygen content of the inhaled nitrox mix should be raised by flushing the breathing loop with oxygen. This process involves successive nitrox replacement until a defined constant and stable oxygen content level is reached that is higher than the critical assumptions ${ }^{23}$. The original oxygen flushing procedure approved for the study was based on making 3 inhalations from the apparatus loop and then venting the exhaled gas, followed by 3 inhalations and exhalations into the apparatus. This activity had to be repeated until the expected effect was achieved, Tab.1.

Types of breathing loop flushing in the SCR CRABE apparatus ${ }^{24}$. Source: Kłos R, Szymański R, Konarski M, Woźniak A, Temporary decompression guidelines for the $\mathrm{Nx} / \mathrm{O}_{2}$ SCR Crabe Scuba diving apparatus. Gdynia 2018

Rinsing Rinsing with oxygen or nitrox consists in making 3 inhalations from the breathing space of the device and exhales with the nose out into the water. Flushing with oxygen or nitrox may be performed 1, 2, 3 or more times depending on the moment of the dive.

Oxygen rinsing rinsing with oxygen consists in enriching the current breathing mix with a mixture containing at least 90\% O_2 and is performed from a depth of $15 \mathrm{mH} \_2 \mathrm{O}$ to the first decompression stop and at the first decompression stop, the time of which is included in the decompression course presented in the decompression table. The procedure of rinsing the breathing space of the apparatus with oxygen consists in taking 3 inhalations from the breathing space of the apparatus and exhaling with the nose out into the water. Then the diver takes 3 inhales and exhales through his mouth into the breathing space of the apparatus. This operation should be performed 3 times.

Nitrox rinsing rinsing with nitrox consists in enriching the circulating nitrox with oxygen above the content indicated in the decompression tables, the time of which is included in the course of diving and the decompression process. The procedure of rinsing the breathing space of the apparatus with nitrox consists in taking 3 inhalations from the breathing space of the apparatus and exhaling with the nose out into the water. This operation must be performed once.

In the developed diving technology, oxygen decompression is carried out in the water column according to the example schedule of Tab. 2, after the breathing loop has been flushed with oxygen from the diving apparatus or in an open system using the $X B S^{25}$. The oxygen decompression procedure requires effective flushing of the breathing loop with oxygen from depth of $15 \mathrm{mH}_{2} \mathrm{O}$ so that at the depth of $12 \mathrm{mH}_{2} \mathrm{O}$ (or first oxygen decompression station) the oxygen concentration in the breathing loop of the diving apparatus required by the schedule is achieved. It is assumed that oxygen decompression should be preceded by flushing the breathing loop of the apparatus with oxygen from a depth of $15 \mathrm{mH}_{2} \mathrm{O}$ regardless of whether it is provided for in the decompression schedule as a decompression station or not [5].

The tables for designing decompression schedules use the following assumptions for oxygen decompression:

$\checkmark \quad$ accelerated decompression is calculated only as oxygen decompression,

$\checkmark$ it is not possible to completely flush out the residual nitrogen content from the breathing loop of the apparatus,

$\checkmark$ oxygen decompression requires an oxygen concentration in the inhaled breathing gas to be at least at the level of $\geq[90] \% v O_{2}$,

$\checkmark \quad$ only temporary drops in the oxygen content of $<$ $0,5 \mathrm{~min}$ to the content between $[85 ; 90] \% \mathrm{v}_{2}$ at the first oxygen decompression station. In any other case, additional oxygen flushing of the breathing loop of the apparatus must be undertaken in order to raise the oxygen content to the level of $\geq[90] \% v O_{2}$. If the oxygen content of $\geq 90 \% v \mathrm{O}_{2}$ cannot be maintained, equivalent decompression should be applied. 
Decompression schedule for the SCR Crabe apparatus. Source: Kłos R, Szymański R, Konarski M, Woźniak A, Temporary decompression guidelines for the $\mathrm{N} x / \mathrm{O}_{2}$ SCR Crabe Scuba apparatus. Gdynia 2018.

\begin{tabular}{|c|c|c|c|c|c|c|c|c|c|}
\hline \multicolumn{10}{|c|}{$\begin{array}{l}\text { Nitrox: } 32,5_{-0,5}^{+0} \%{ }_{v} \mathrm{O}_{2} \\
\text { The rate of compression } v \leq 20 \mathrm{mH}_{2} \mathrm{O} \cdot \mathrm{min}^{-1} \\
\text { The speed of the transition between Deco stops } \cong 3 \mathrm{mH}_{2} \mathrm{O} \cdot \mathrm{min}^{-1}\end{array}$} \\
\hline \multirow{4}{*}{ Depth } & \multirow{4}{*}{$\begin{array}{l}\text { Bottom } \\
\text { Time }\end{array}$} & \multirow{4}{*}{$\begin{array}{l}\text { Time to } \\
\text { first deco } \\
\text { stop }\end{array}$} & \multicolumn{6}{|c|}{$\begin{array}{c}\text { Deco stops } \\
{\left[\mathrm{mH}_{2} \mathrm{O}\right]}\end{array}$} & \multirow{4}{*}{$\begin{array}{c}\text { Total deco } \\
\text { time }\end{array}$} \\
\hline & & & \multicolumn{2}{|c|}{$N x(1)$} & \multicolumn{4}{|c|}{$\mathrm{O}_{2}$ (ㄱ) } & \\
\hline & & & 18 & 15 & 12 & 9 & 6 & 3 & \\
\hline & & & \multicolumn{6}{|c|}{ Deco time } & \\
\hline$\left[\mathrm{mH}_{2} \mathrm{O}\right]$ & {$[\mathrm{min}]$} & {$[\mathrm{min}]$} & \multicolumn{6}{|c|}{$[\mathrm{min}]$} & {$[\mathrm{min}]$} \\
\hline \multirow{4}{*}{ Basic decompression } & 10 & \multirow{4}{*}{4} & - & - & 1 & 1 & 1 & 1 & 9 \\
\hline & 15 & & - & - & 1 & 1 & 2 & 3 & 12 \\
\hline & 20 & & - & 1 & 2 & 2 & 3 & 7 & 20 \\
\hline & 25(5) & & - & 2 & 3 & 3 & 4 & 14 & 31 \\
\hline \multirow{4}{*}{$\begin{array}{c}\text { Acceleration of } \\
\text { decompression }(4)\end{array}$} & $20(4$ & \multirow{4}{*}{4} & - & 1 & 2 & 2 & 3 & 6 & 19 \\
\hline & $25(4)$ & & - & 2 & 3 & 3 & 4 & 10 & 27 \\
\hline & $30 \oplus$ & & 1 & 3 & 3 & 4 & 6 & 12 & 34 \\
\hline & $35(4)$ & & 2 & 4 & 4 & 4 & 9 & 15 & 43 \\
\hline \multicolumn{10}{|c|}{$\begin{array}{l}\text { (1) minimum concentration of } \mathrm{O}_{2} \text { level }>23,4 \% \mathrm{O}_{2} \\
\text { (2) minimum concentration of } \mathrm{O}_{2} \text { level } \geq 90 \% \mathrm{O}_{2} \\
\text { (3) includes } 1 \text { min transition time from } 3 \mathrm{mH}_{2} \mathrm{O} \text { deco stop to the surface } \\
\text { (4) profile not recommended without additional protection by the } \mathrm{XBS} \text {, because the use of emergency } \mathrm{Nx} \\
\text { decompression as double the time for oxygen decompression is associated with an increased risk of } \\
\text { decompression sickness } \\
\text { (5) profile not recommended without additional protection by the } \mathrm{XBS} \text {, because the use of emergency } \mathrm{Nx} \\
\text { decompression as double the time for oxygen decompression is associated with long duration time under } \\
\text { the water } \geq 60 \mathrm{~min})\end{array}$} \\
\hline
\end{tabular}

Achieving a defined constant and stable oxygen level results from the decompression assumptions made. Maintaining oxygen concentration in the inhaled breathing gas at the level of $\geq[90] \% v \mathrm{O}_{2}$ is the most important from the point of view of decompression safety, and therefore the success of the dive. From the point of view of implementing the device flushing process, it should be noted that temporary drops of $<0,5 \mathrm{~min}$ to the content of $[85 \div 90] \% v O_{2}$ between the first oxygen decompression station were allowed. If the assumptions made for the research are not met, the probability of a $D C S$ risk incidence increases.

\section{RESEARCH}

As mentioned above, the stabilisation of the breathing gas composition in the breathing loop of the apparatus during the decompression phase depends on the process of dynamic mixing of nitrox with oxygen. Oxygen flushing does not guarantee the immediate state of balance. During the experiment it was observed that the efficiency of flushing increased with the frequency of performing the flushing procedure, while its relative effectiveness decreased with the increased number of performed repetitions.

The basis for deriving a relation [1] of oxygen content $x_{j}$ as a function of the repeated flushing performance $j$ is the molar balance of oxygen and the whole volume of the breathing gas. This balance is presented in Tab. 3.

$$
x_{j}=x_{w}+\left(x_{0}-x_{w}\right) \cdot\left(\frac{V_{z}}{V_{c}}\right)^{j}
$$

where: $V_{c}$ - total volume of the breathing loop $\left[\mathrm{dm}^{3}\right], V_{z}-$ total residual volume in the breathing loop $\left[\mathrm{dm}^{3}\right], x_{0}$ - initial oxygen content in the breathing bag expressed by a molar fraction $\left[\mathrm{mol} \cdot \mathrm{mol}^{-1}\right], x_{w}-$ a molar fraction of oxygen in the premix $\left[\mathrm{mol} \cdot \mathrm{mol}^{-1}\right], j-$ number of flushing repetitions in the breathing loop.

The relation [1] shows the independence of oxygen content $x_{j}$ after a flushing repeated $j$ - times in the breathing loop from the depth of $x_{j} \neq f(H)$ [8].

The presented molar balance of oxygen and premix results from the process of exchanging the breathing gas in the loop of the diving apparatus in its flushing phase. On the basis of the balance and the relationship between the oxygen content $x_{j}$ as a function of the number of flushing repetitions, theoretical calculations can be made as a basis for further process verification. 
The molar balance of oxygen and breathing gas in the process of flushing the breathing loop.

Removing

\begin{tabular}{cccc} 
& Arrives & - & $\frac{p}{p_{0}} \cdot\left(V_{c}-V_{z}\right) \cdot x_{w}$ \\
\cline { 2 - 4 } Oxygen & Decline & $\frac{p}{p_{0}} \cdot\left(V_{c}-V_{z}\right) \cdot x_{i}$ & - \\
\cline { 2 - 4 } & Remains & $\frac{p}{p_{0}} \cdot V_{z} \cdot x_{i}$ & $\frac{p}{p_{0}} \cdot V_{z} \cdot x_{i}+\left(V_{c}-V_{z}\right) \cdot x_{w}$ \\
\cline { 2 - 4 } Nitrox & Arrives & - & $\frac{p}{p_{0}} \cdot\left(V_{c}-V_{z}\right)$ \\
\cline { 2 - 4 } & Decline & $-\left(V_{c}-V_{z}\right)$ & - \\
\cline { 2 - 4 } & Remains & $\frac{p}{p_{0}} \cdot V_{z}$ & $\frac{p}{p_{0}} \cdot V_{c}$
\end{tabular}

where: $V_{c}$ - total volume of the breathing loop $\left[\mathrm{dm}^{3}\right], V_{z}$ - total residual volume in the breathing loop [ $\left.\mathrm{dm}^{3}\right], x_{0}-$ initial oxygen content in the breathing bag expressed by a molar fraction $\left[\mathrm{mol} \cdot \mathrm{mol}^{-1}\right], x_{w}-$ a molar fraction of oxygen in the premix $\left[\mathrm{mol}^{\prime} \cdot \mathrm{mol}^{-1}\right], j-$ number of flushing repetitions in the breathing loop [8]

During the works carried out in the laboratory, the theoretical assumptions made for the modified procedures for flushing the breathing loop of the $S C R C R A B E$ apparatus were verified on the basis of the $D G K N-120$ measurement system, Fig. 3. Test-stand measurements, although less accurate than laboratory measurements, are assumed to be sufficiently reliable for the assessment of the limits of critical variation of the stable oxygen value.

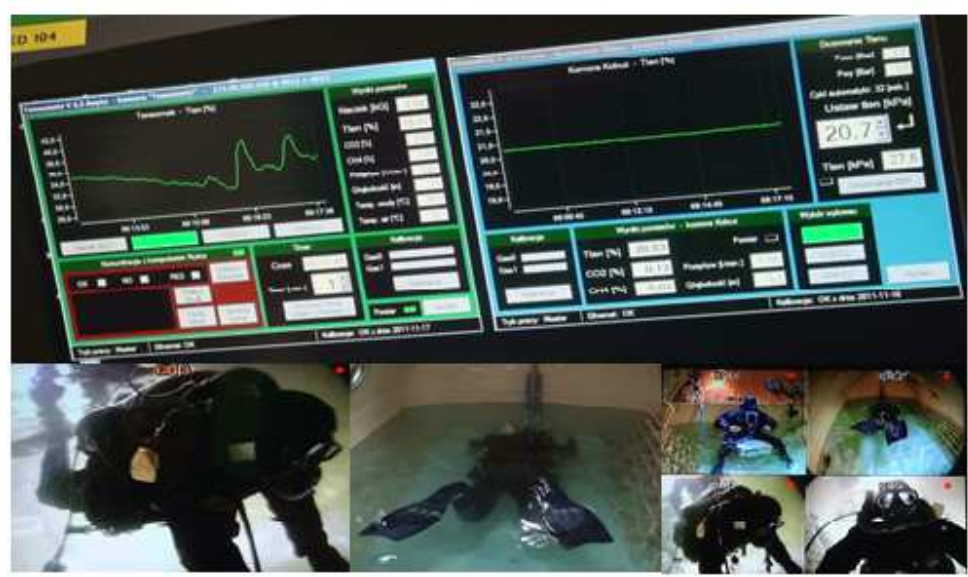

Fig. 3 The general view of the control station of the $D G K N-120$ measurement system in ZTPP AMW. Source: own work.

Modifications of the process of oxygen flushing in the breathing loop of the SCR CRABE apparatus are presented in Tab. 4. In the course of experiments, six variants of parameter modification in the analysed process were evaluated. At present, the research is focusing on variant no.VI Tab.4. 
Methods of flushing the breathing loop of the SCR CRABE diving apparatus with premix. Source: own study based on the results of research No.: DOBR-BIO8 / 09/01/2016, entitled: "Designing decompression for MCM / EOD II dives".

\begin{tabular}{|c|c|c|c|c|c|c|c|}
\hline $\mathrm{Nr}$ & $\begin{array}{l}\text { Stages of flushing the } \\
\text { diving apparatus }\end{array}$ & $\begin{array}{c}\text { Diving } \\
\text { No } 2 \\
\text { Diver } \\
\text { ECHO } \\
\text { Date:26.10.2017 }\end{array}$ & $\begin{array}{c}\text { Diving } \\
\text { No } 8 \\
\text { Diver } \\
\text { DELTA } \\
\text { Date:08.11.2017 } \\
\end{array}$ & $\begin{array}{c}\text { Diving } \\
\text { No } 35 \\
\text { Diver } \\
\text { CHARLIE } 2 \\
\text { Date: } 24.03 .2018 \\
\end{array}$ & $\begin{array}{c}\text { Diving } \\
\text { No } 38 \\
\text { Diver } \\
\text { CHARLIE } \\
\text { Date:04.04.2018 } \\
\end{array}$ & $\begin{array}{c}\text { Diving } \\
\text { No } 70 \\
\text { Diver } \\
\text { ALFA } \\
\text { Date: } 10.09 .2018 \\
\end{array}$ & $\begin{array}{c}\text { Diving } \\
\text { No 71 } \\
\text { Diver } \\
\text { BRAVO } \\
\text { Date: } 12.09 .2018 \\
\end{array}$ \\
\hline 1 & $\begin{array}{l}\text { Breathing from } \\
\text { apparatus } N x \text { before } \\
\text { diving }\end{array}$ & $10 \mathrm{~min}$ & $10 \mathrm{~min}$ & $5 \mathrm{~min}$ & $5 \min$ & $3 \min$ & $3 \min$ \\
\hline 2 & $\begin{array}{l}\text { Exhausts from the } \\
\text { moment the } \\
\text { compression starts } \\
\text { - rinsing } N x\end{array}$ & 5 & 5 & 3 & 3 & 3 & 3 \\
\hline 3 & $\begin{array}{l}\text { Exhaust when exceeded } \\
5 \mathrm{~m} \mathrm{H}_{2} \mathrm{O} \text {-rinsing } \mathrm{Nx}\end{array}$ & . & - & 5 & 3 & (n............. & ....... \\
\hline 4 & $\begin{array}{l}\text { Exhaust when exceeded } \\
10 \mathrm{~m} \mathrm{H}_{2} \mathrm{O} \text { - rinsing } \mathrm{Nx}\end{array}$ & . & . & (n)............ & . & 3 & 3 \\
\hline 5 & $\begin{array}{l}\text { The last minute bottom } \\
\text { time - rinsing } N x\end{array}$ & $\begin{array}{c}1 \text { rinsing } \\
(1 \cdot 3)\end{array}$ & $\begin{array}{c}1 \text { rinsing } \\
(1 \cdot 3)\end{array}$ & $\begin{array}{c}1 \text { rinsing } \\
(1 \cdot 3)\end{array}$ & $\begin{array}{c}1 \text { rinsing } \\
(1 \cdot 3)\end{array}$ & 1 rinsing & 1 rinsing \\
\hline \multicolumn{8}{|c|}{ Rinsing of $\mathrm{O}_{2}, h=15 \div 12 \mathrm{mH}_{2} \mathrm{O}$. } \\
\hline 6 & $\begin{array}{l}\text { Apparatus rinsing } \mathrm{O}_{2} \\
\text { at the time of reaching } \\
12 \mathrm{mH}_{2} \mathrm{O} \text {. }\end{array}$ & $\begin{array}{l}3 \text { rinsing } \\
(3 \cdot 3)\end{array}$ & & & & & \\
\hline 7 & $\begin{array}{l}\text { Apparatus rinsing } \mathrm{O}_{2} \\
\text { at the time of } \\
\text { transition } \\
15 \div 12 \mathrm{mH}_{2} \mathrm{O} \text {. }\end{array}$ & & $\begin{array}{c}3 \text { rinsing } \\
(3 \cdot 3)\end{array}$ & $\begin{array}{c}3 \text { rinsing } \\
(3 \cdot 3)\end{array}$ & & & \\
\hline 8 & $\begin{array}{l}\text { Apparatus rinsing } \mathrm{O}_{2} \\
\text { from } 15 \mathrm{mH}_{2} \mathrm{O} \text { - last } \\
\text { minute of the stop }\end{array}$ & & & & $\begin{array}{c}3 \text { rinsing } \\
(3 \cdot 3)\end{array}$ & $\begin{array}{c}3 \text { rinsing } \\
(3 \cdot 3)\end{array}$ & $\begin{array}{l}4 \text { rinsing } \\
(4 \cdot 3)\end{array}$ \\
\hline
\end{tabular}

During the implementation of the changes, the obtained distributions of data measuring oxygen content in the breathing loop of the apparatus were observed and analysed. The distribution of changes in percentage oxygen concentration in the breathing loop of the apparatus, oxygen partial pressure and diving depth for the diver $E C H O$, and $N x 0.325^{26}$ were presented in Fig. 4.

The marked feature points $1-427$ indicate the key elements of the apparatus flushing process with premix and oxygen during the dive.

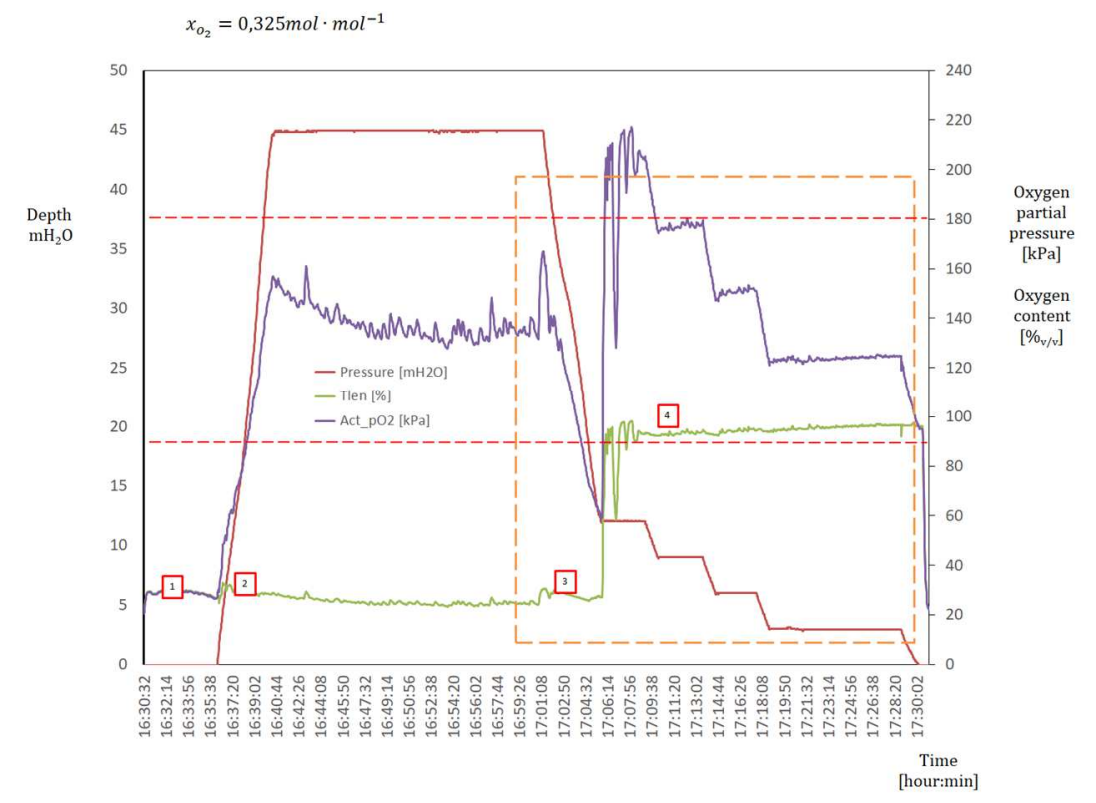


$x_{o_{2}}=0,325 \mathrm{~mol} \cdot \mathrm{mol}^{-1}$

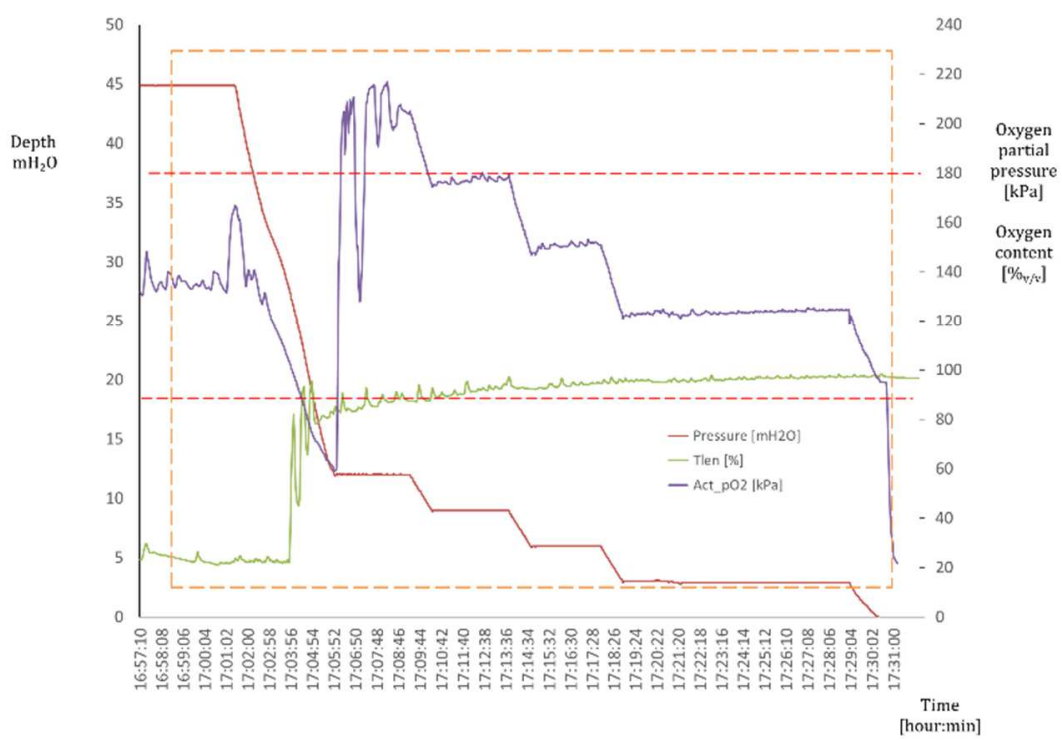

Figures 4 and 5. Total and fragmentary distribution of breathing gas composition parameters in the breathing bag of the $N x-S C R C R A B E$ apparatus during a stay at the bottom and decompression for the Echo diver, dive no. 2 dated 26.10 .2017 , nitrox $x_{o_{2}}=0,325 \mathrm{~mol} \cdot \mathrm{mol}^{-1}$, breathing loop flushing during oxygen decompression phase $x_{\mathrm{O}_{2}}=1,0 \mathrm{~mol} \cdot \mathrm{mol}^{-1}$. Profile $45 \mathrm{~m} / 25 \mathrm{~min}$, stay at the bottom 25 minutes, diving time 54 minutes. Source: own work based on the results of research no: DOBR-BIO8/09/01/2016.

For further analysis, the range of data determined by the last flushing limit before commencing the final ascent was adopted - Item 3. Fig. 4. The obtained fragmentary distribution for dive no. 2 (Tab. 4) and the procedure of repeating the oxygen flushing procedure 3 times is shown in (Fig. 5).

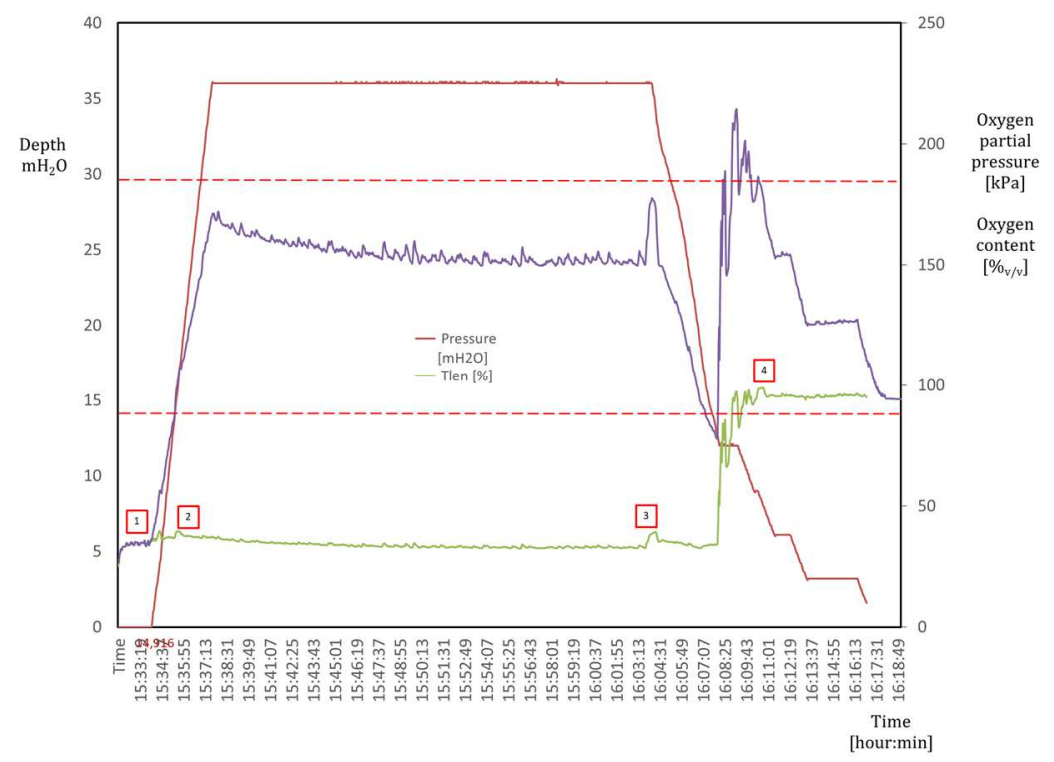




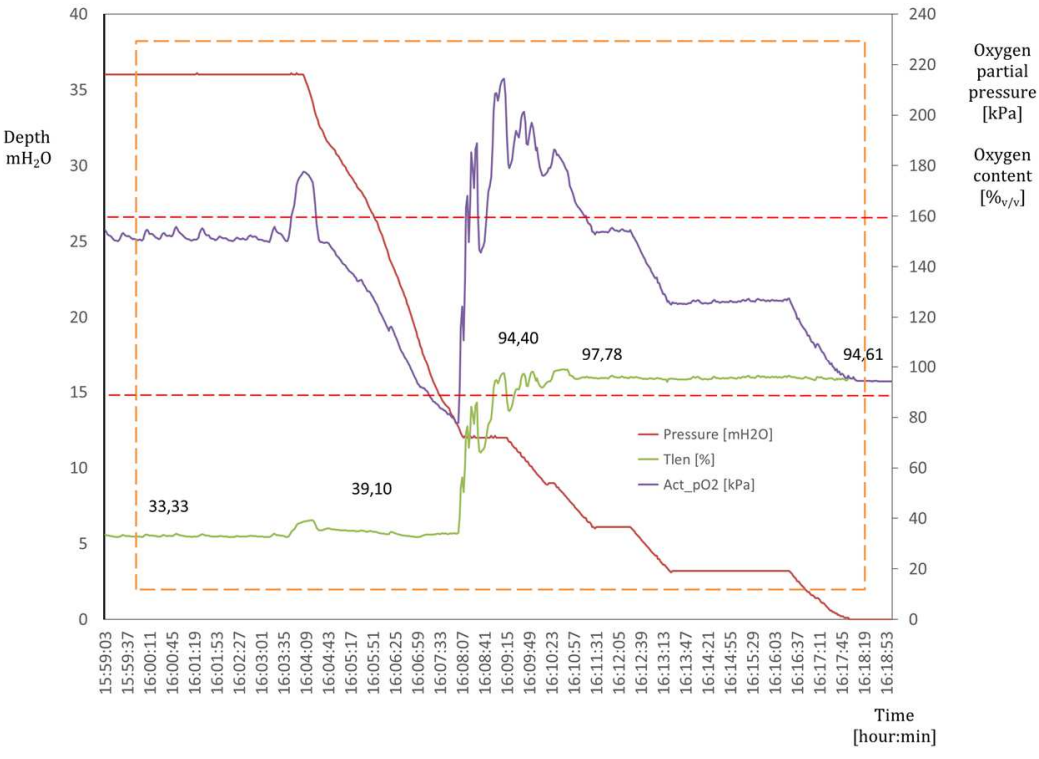

Figures 6 and 7. Total and fragmentary distribution of breathing gas composition parameters in the breathing bag of the $N x-S C R C R A B E$ apparatus during a stay at the bottom and decompression for the Bravo diver, dive no. 71 dated 12.09 .2018 , nitrox $x_{O_{2}}=0,4 \mathrm{~mol} \cdot \mathrm{mol}^{-1}$, breathing loop flushing during oxygen decompression phase $x_{\mathrm{o}_{2}}=1,0 \mathrm{~mol} \cdot \mathrm{mol}^{-1}$. Profile $36 \mathrm{~m} / 30 \mathrm{~min}$, stay at the bottom 30 minutes, diving time 44 minutes. Source: own work based on the results of research no: DOBR-BIO8/09/01/2016.

Fig. 6 shows an analogous distribution for flushing process modifications for dive no. 71 (Tab. 4) and premix $N x 0,4^{28}$. The main differences of the presented observations are related to the application of different flushing procedures and the composition of the primary premix in the breathing loop of the apparatus before the procedure is performed. From the obtained data distribution, the range of measurement data presented in Fig. 7 was singled out for analysis. The measurement data reflect the course of the process for the flushing procedure repeated 4 times.

In each case the oxygen flushing of the breathing loop of the apparatus increased its content to the level of $\geq[90] \% v O_{2}$. The modification of the procedure resulted in an increase of the oxygen content in the breathing loop of the apparatus. In both cases, the time taken to increase the oxygen concentration to a value $\geq[90] \% \mathrm{O}_{2}$ differs, as does the value of the stable oxygen content during the oxygen decompression phase. Changes in oxygen concentration in each stage of the flushing process are marked on the chart. The highest value of oxygen concentration observed after the completion of the oxygen flushing process was $C_{O_{2}}=97,78 \% v$ in the decompression phase this value gradually decreases to the minimum value $C_{O_{2}}=94,61 \% v>C_{O_{2}} \min =90 \% v$. The distribution of oxygen content changes for 4 flushing procedures and the $\mathrm{N} x 32,5 \% \mathrm{O}_{2}$ mixture during each experimental dive is shown in Fig. 8.

The figure shows the specification limit $C_{\mathrm{O}_{2}} \min \geq$ $90 \% v_{2}$ resulting from critical assumptions for the decompression schedule. The vertical line limits the area subjected to further analysis in terms of stable oxygen content in order to identify the process changes taking place. It was assumed that the observations made should be treated as preliminary studies ${ }^{29}$, which are the basis for further conclusions. Differences in decomposition are revealed in the initial phase of stabilisation of the breathing gas content after oxygen flushing. Although the stable oxygen content is similar in the final phase of oxygen decompression, the rate of increase in oxygen concentration varies. 


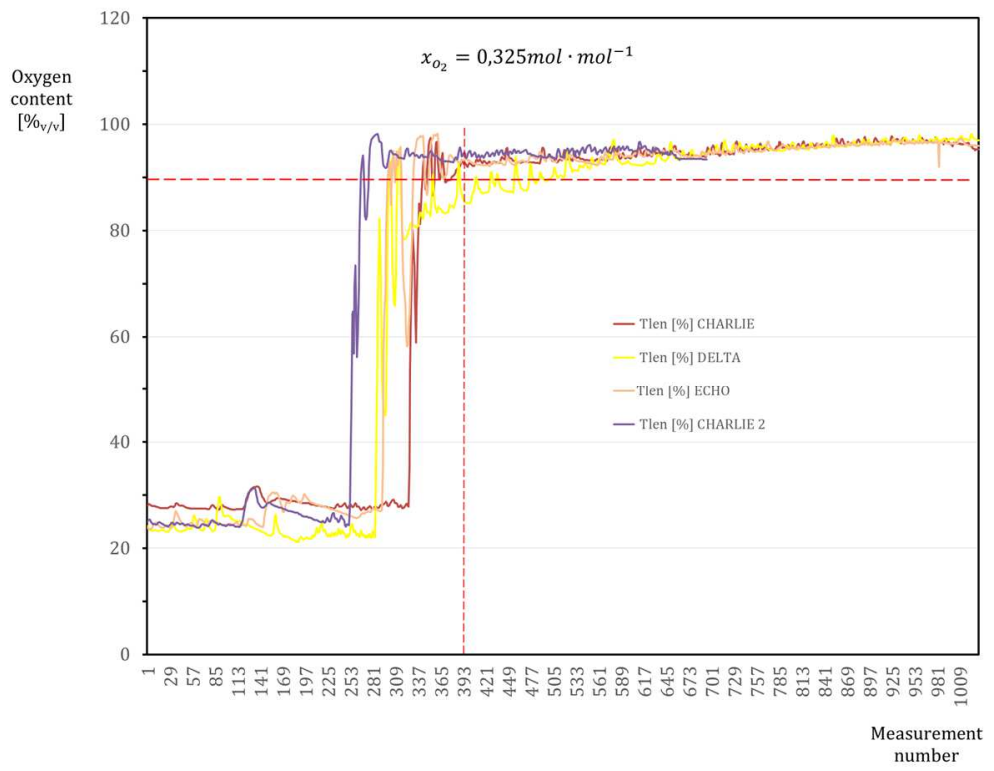

Fig. 8 The parameters of breathing gas composition in the breathing bag of the $N x-S C R C R A B E$ apparatus for $n=4$ nitrox divings $x_{O_{2}}=0,325 m o l \cdot m o l^{-1}$ during the flushing of the breathing loop in the oxygen decompression phase $x_{O_{2}}=1,0 \mathrm{~mol} \cdot \mathrm{mol}^{-1}$ before and after the modification of the flushing procedure Source: own work based on the results of research no: DOBR-BIO8/09/01/2016.

Fig. 9 shows the distribution of oxygen content changes for 2 modified flushing procedures for divers Alfa and Bravo for $N x 0,4$. The observations indicate the differences occurring before and after the change in the flushing procedure. In the case of diver Bravo, the resulting distribution of measurement data indicates a higher stable oxygen content in the breathing bag.

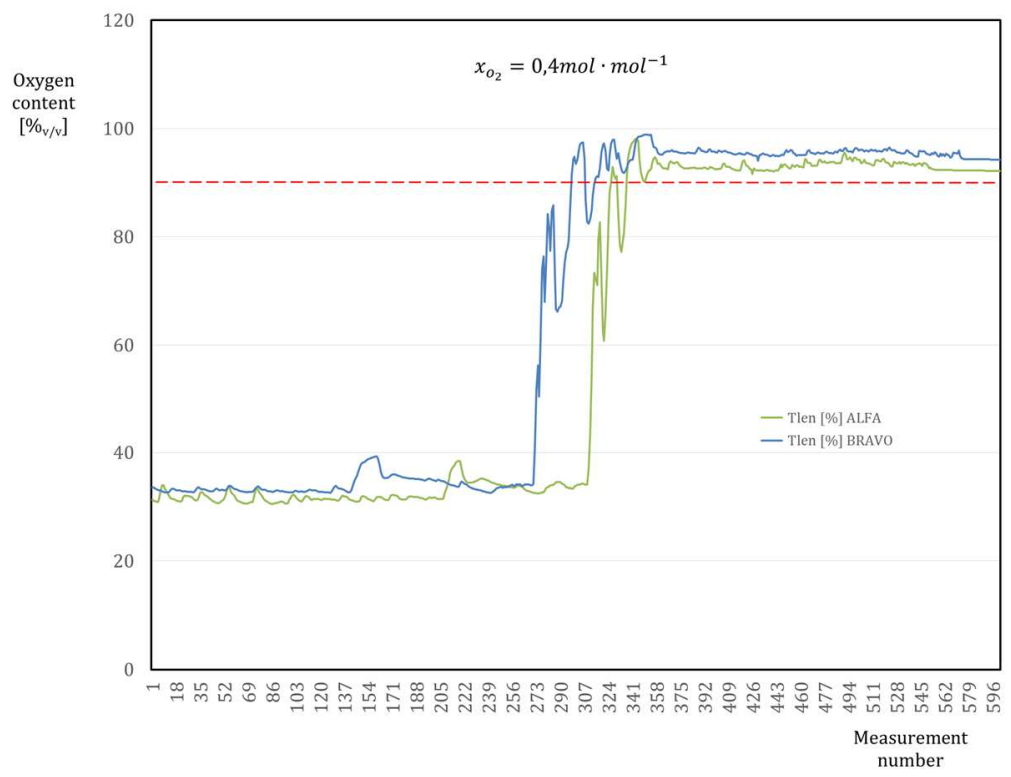

Fig. 9 The parameters of breathing gas composition in the breathing bag of the $N x-S C R C R A B E$ apparatus for $n=2$ nitrox divings $x_{o_{2}}=0,4 m o l \cdot m o l^{-1}$ during the flushing of the breathing loop in the oxygen decompression phase $x_{O_{2}}=1,0 \mathrm{~mol} \cdot \mathrm{mol}^{-1}$ before and after the modification of the flushing procedure. Source: own work based on the results of research no: DOBR-BIO8/09/01/2016. 
The distributions for each modification of the flushing procedure are shown in Fig. 10. The distributions have different shapes and in some cases a number of outliers ${ }^{30}$ can be identified. Most of them show significant asymmetry except for the Bravo distribution.

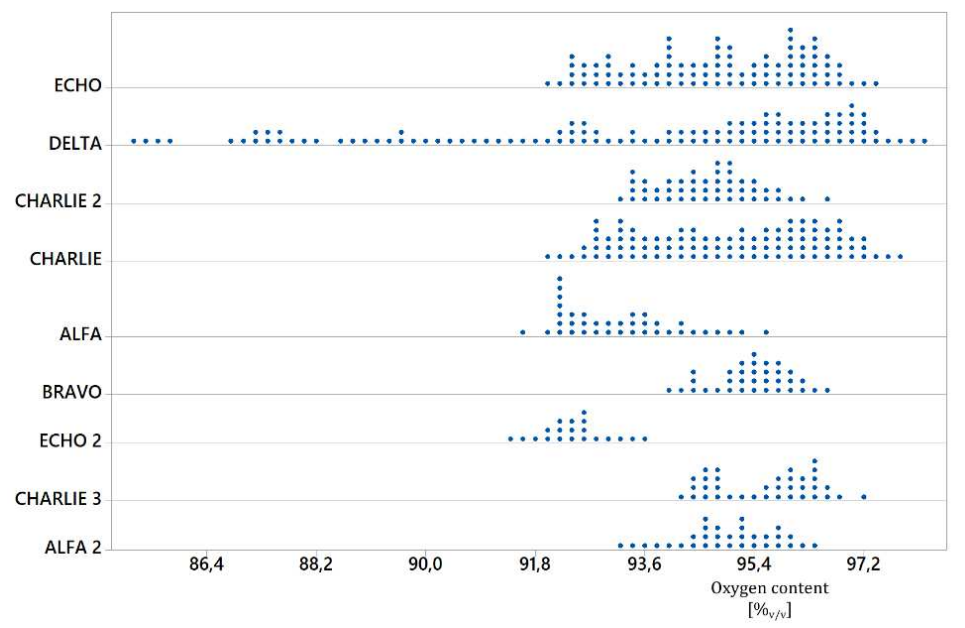

Fig. 10 The point chart of the distribution of measurement data of stable oxygen content in the breathing bag after the completion of the flushing of the breathing loop during the oxygen decompression phase $x_{o_{2}}=1,0 \mathrm{~mol} \cdot \mathrm{mol}^{-1}$ for nitrox $x_{O_{2}}=0,4 \mathrm{~mol} \cdot \mathrm{mol}^{-1}$ and $x_{o_{2}}=0,325 \mathrm{~mol} \cdot \mathrm{mol}^{-1}$. Source: own work based on the results of research no: DOBR-BIO8/09/01/2016.

Fig. 11. Shows the changes in the position of the mean value $\bar{x}$ of each distribution of stable oxygen content after the end of the process of flushing the apparatus. The observations enable the search for deterministic causes of the differences in the context of modifying the input variables and process parameters. The obtained empirical distributions confirm that the best properties are represented by the Bravo distribution. This initially confirms the expected direction of changes. While drawing conclusions, attention should be paid to comparing them for the same type of premix mixture, as it is natural that it is beneficial to shift the mean values of oxygen content $\bar{x}_{O_{2}}$ during the decompression phase with a premix with higher oxygen content. In this case, the stable oxygen content before starting to flush the breathing loop of the apparatus during a stay at the bottom is higher - and therefore the flushing process is more efficient.

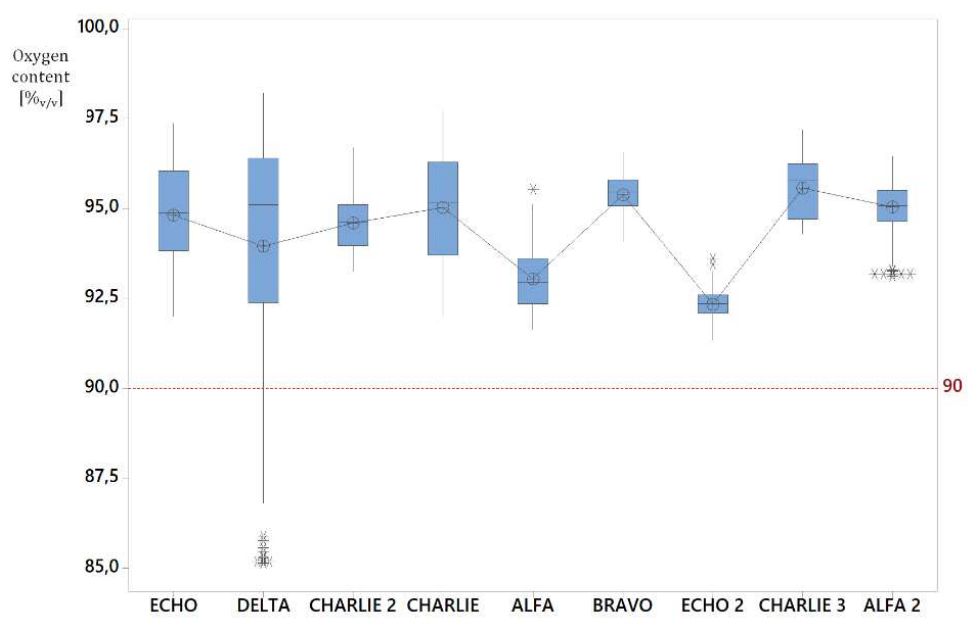

Fig. 11 The distribution of $\bar{x}$ measurement values, lower and upper quartile, the range of variation of measurements and outliers of stable $O_{2}$ content in the breathing bag after the completion of flushing the breathing loop of the apparatus with oxygen $x_{O_{2}}=1,0 \mathrm{~mol}^{\prime} \cdot \mathrm{mol}^{-1}$ for nitrox $x_{\mathrm{O}_{2}}=0,4 \mathrm{~mol} \cdot \mathrm{mol}^{-1}$ and $x_{\mathrm{O}_{2}}=$ $0,325 \mathrm{~mol} \cdot \mathrm{mol}^{-1}$. Distribution of $\mathrm{n}=6$ oxygen flushing procedures of the apparatus at the decompression depth from $h=12-15 \mathrm{mH}_{2} 0$. Source: own work based on the results of research no: DOBR-BIO8/09/01/2016. 
To compare the nature of the changes taking place, Fig. 12 shows the histogram of $O_{2}$ measurements in the SCR CRABE breathing bag for two dives of the same diver marked as Alf $a$ and Alf 2 (respectively: before and after the modification of the diving apparatus flushing procedure.) It was shown that the average value of the $\bar{x}_{O_{2}}$ process was favourably and significantly shifted towards higher values of oxygen concentrations in the breathing loop of the apparatus for the assumed $(1-\alpha=0,95)$ and the number of degrees of freedom $n>100$. The standard deviation of the analysed comparative distributions has not been significantly reduced. The distribution of process variability in both cases is within the established tolerance limits.

The distribution before the modification is more shifted towards the lower tolerance LCL ${ }^{31}=90 \%{ }_{v} O_{2}$. Such behaviour is not favourable to the previously adopted decompression assumptions, because the possibility of lowering the expected stable oxygen content towards the lower limit may have a negative impact on the effectiveness of the conducted decompression. The distribution after the modification shows that there is a potential to achieve higher process capacity after the identification of deterministic factors that influence its shift and instability ${ }^{32}$. Reduction of variability and dispersion is important from the point of view of process capability, and therefore keeping it close to its expected nominal value 33 within controlled limits. From the presented distributions of Fig. 9 it should be concluded that the modification of the procedure that consists in the introduction of a 4-fold oxygen flushing procedure in the apparatus causes significant changes in the process of flushing the apparatus made by the same diver with the same premix mixture.

After the identification and elimination of the occurring deterministic causes interfering with the process under consideration, there is a possibility of further improvement of its capacity. The possibility of improvement is shown by the difference between the potential and observed variability ${ }^{34}$ Fig. 12 .

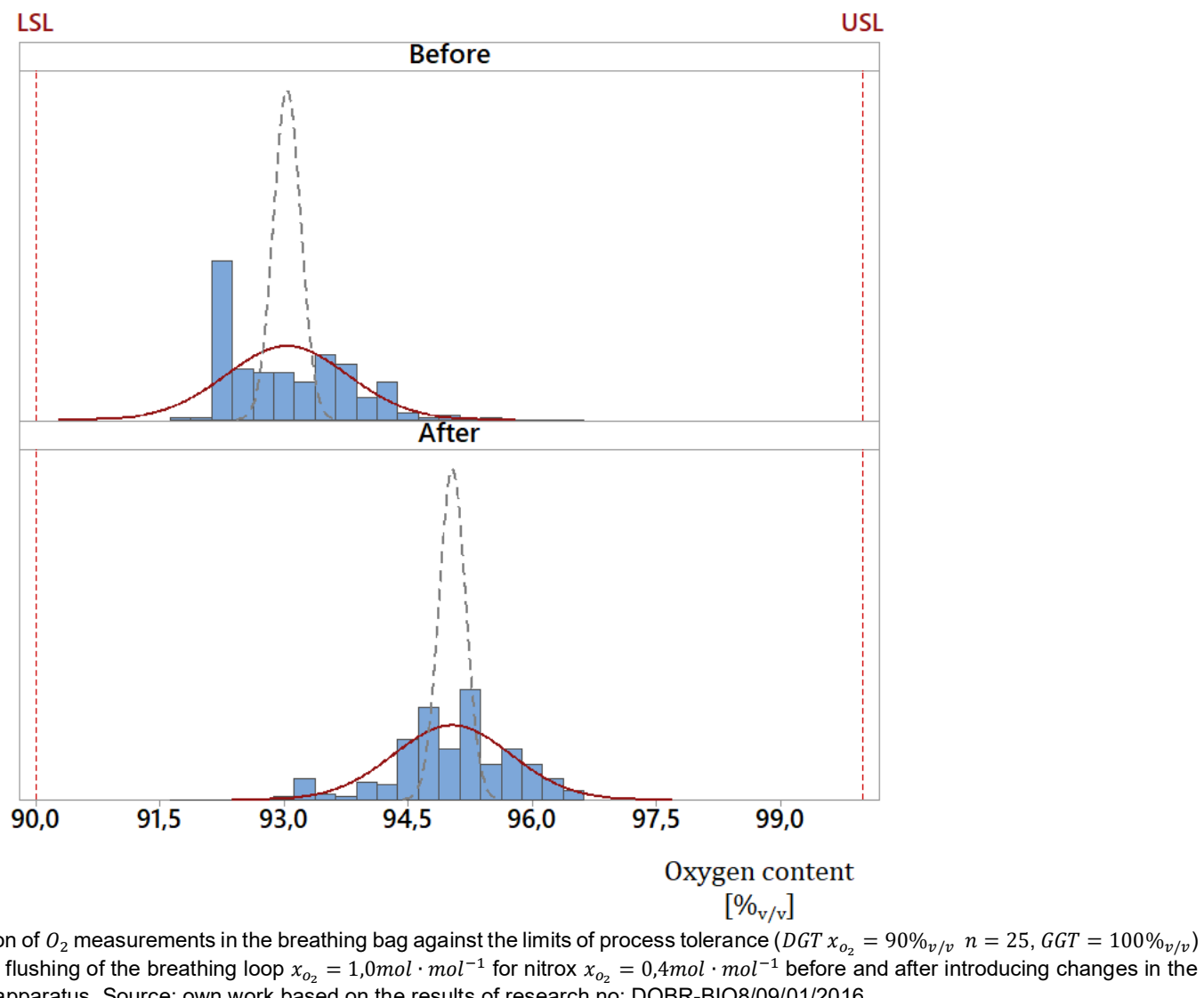

Fig. 12 The empirical distribution of $O_{2}$ measurements in the breathing bag against the limits of process tolerance $\left(D G T x_{o_{2}}=90 \%_{v / v} n=25, G G T=100 \%_{v / v}\right)$
after the completion of oxygen flushing of the breathing loop $x_{O_{2}}=1,0 \mathrm{~mol} \cdot \mathrm{mol}^{-1}$ for nitrox $x_{O_{2}}=0,4 \mathrm{~mol} \cdot \mathrm{mol}^{-1}$ before and after introducing changes in the process of flushing the diving apparatus. Source: own work based on the results of research no: DOBR-BIO8/09/01/2016.

Fig. 13 Shows the histogram of oxygen content measurement data in SCR CRABE for divers Alf $a^{35}$ and $B r a v o$. The graph indicates that it is possible to maintain a stable distribution of oxygen content within the defined tolerance limits, and thus to obtain a better response of the analysed process after modifying a given parameter ${ }^{36}$. The obtained distribution of variability has the highest $\bar{x}_{O_{2}}$ after the procedure of oxygen flushing in the breathing loop. The changes in the course are similar to those shown in Fig. 12.

In both cases, significant differences in the capacity 37 of the process under analysis were demonstrated. As we know, each process is affected by various dependent and independent factors, which may interfere with its course, when they are only random, it can be concluded that the process is stable and under control. Despite the obtained improvement 38 , it cannot be stated that all deterministic causes interfering with the process have been identified. The data obtained are only the basis for further research and must be confirmed. Deterministic conclusions were made on the basis of empirical studies, as there are not sufficient grounds ${ }^{39}$ for statistical conclusions. 


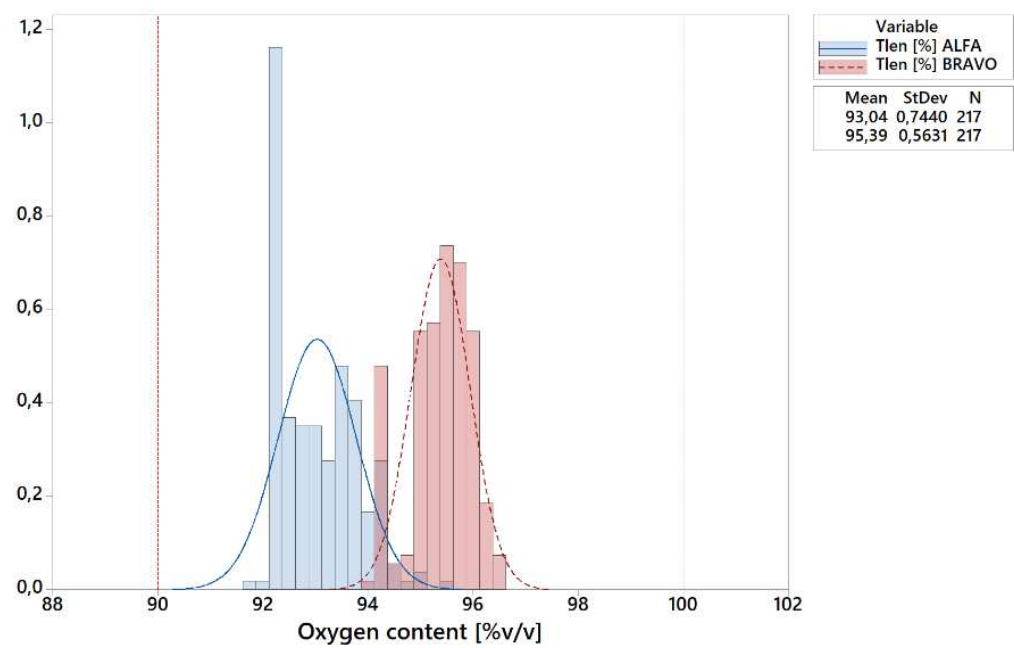

Fig. 13 Histogram of empirical distribution of $O_{2}$ measurements in the breathing bag with tolerance limits $\left(D G T x_{o_{2}}=90 \%{ }_{v / v} n=25, G G T=100 \%{ }_{v / v}\right)$ after the completion of the flushing of the breathing loop with oxygen $x_{o_{2}}=1,0 \mathrm{~mol} \cdot \mathrm{mol}^{-1}$ for nitrox $x_{O_{2}}=0,4 \mathrm{~mol} \cdot \mathrm{mol}^{-1}$. Source: own work based on the results of research no: DOBR-BIO8/09/01/2016.

14. The distributions show the change in their nature in terms of the position of the average oxygen content $\bar{x}_{\mathrm{O}_{2}}$ and the standard deviation of the sample in relation to the determined process limits.
In order to observe the changes resulting from the modification of the $p$-parameter of the flushing procedure Tab. 4, the selected distributions of variations that reveal significant differences at intermediate stages of the implementation of process changes are shown in Fig.

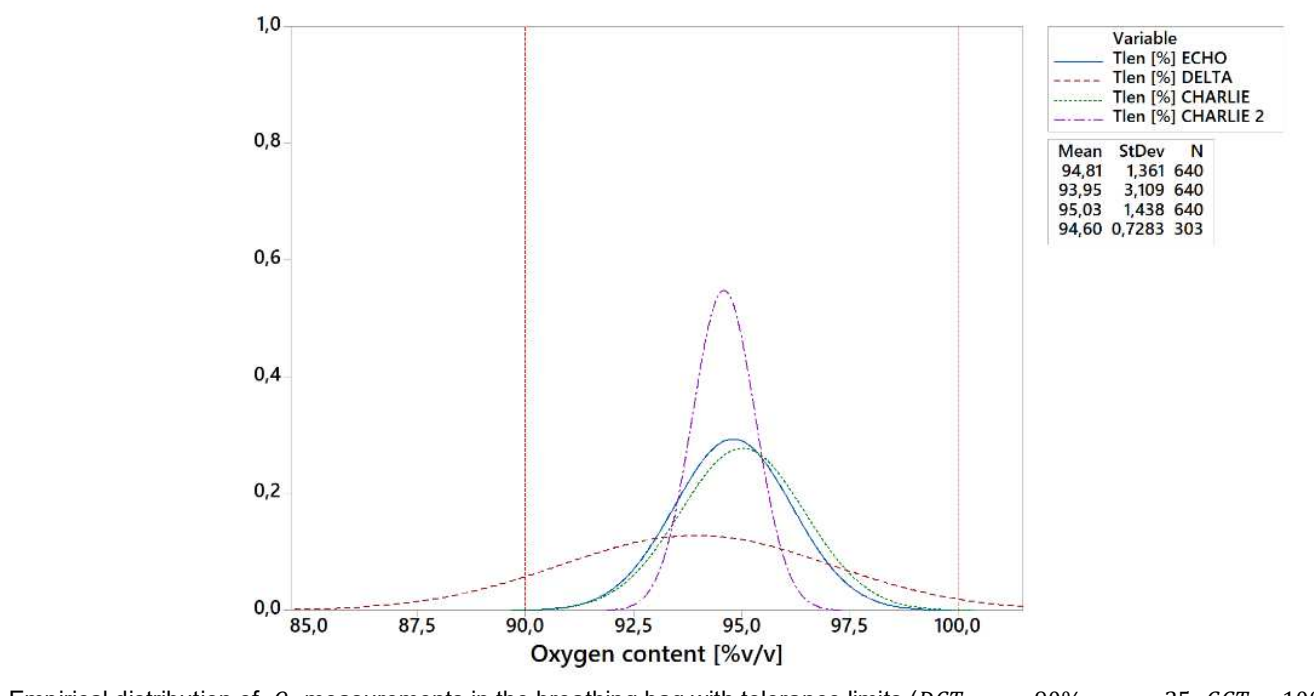

the implementation of proc

Fig. 14 Empirical distribution of $O_{2}$ measurements in the breathing bag with tolerance limits $\left(D G T x_{o_{2}}=90 \%_{v / v} n=25, G G T=100 \%_{v / v}\right)$ after the completion of flushing the breathing loop with oxygen $x_{O_{2}}=1,0 \mathrm{~mol} \cdot \mathrm{mol}^{-1}$ for nitrox $x_{O_{2}}=0,325 \mathrm{~mol} \cdot \mathrm{mol}^{-1}$. Flushing variant I $-\mathrm{V} \mathrm{Tab}$. 4. Source: own work based on the results of research no: DOBR-BIO8/09/01/2016. 


\section{Checking the apparatus \\ Nx cylinder opening}

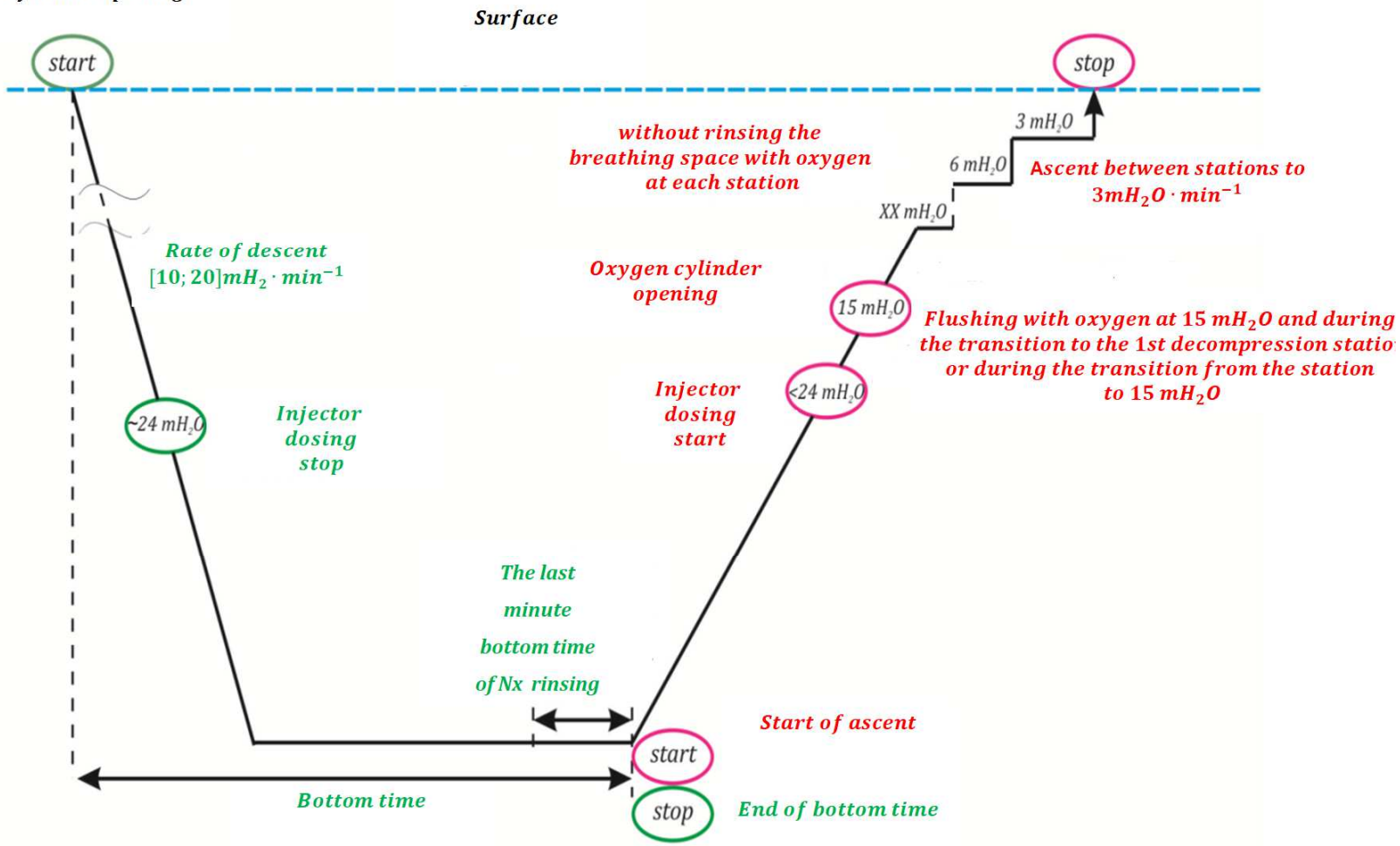

Rys. 15 Modified flushing process for the premix nitrox mixture, the principle of supplying and ventilation of SCR CRABE breathing loop. Source: research results no: DOBR-BIO8/09/01/2016.

As a consequence, a modified procedure algorithm for the procedure of flushing the SCR Crabe with oxygen compliant with the Bravo distribution is proposed for further research in Fig. 15. As a result of process evaluation in the course of implementing the project task, significant modifications were made to the procedures resulting from both the drawn conclusions and operational needs for underwater mine operations ${ }^{40}$.

On the basis of the obtained distributions it can be concluded that it is possible to achieve a higher value than the critical value of $C T Q^{41} C_{O_{2}} \min =90 \% v$ for a stable minimum oxygen content within the limits of
$C_{O_{2}} \in[93,04 \div 95,39] \% v$. In accordance with the procedure, this requires that the flushing of the breathing apparatus is performed at least $n=9 \div 12$ times. This is confirmed by the calculated theoretical oxygen content in the breathing bag in the function of $i$-fold oxygen flushing as shown in Fig. 16.

The diagram has been prepared for different ratios of total volume to residual volume in the breathing loop of the apparatus $V_{Z} / V_{C}$.

$$
\begin{aligned}
& x_{j}=x_{w}+\left(x_{0}-x_{w}\right) \cdot\left(\frac{V_{z}}{V_{c}}\right)^{j} \\
& V_{C}=5,3 \mathrm{dm}^{-3} \\
& x_{w}=1,0 \mathrm{~mol} \cdot \mathrm{mol}^{-1} \\
& x_{0}=0,325 \mathrm{~mol} \cdot \mathrm{mol}^{-1} \\
& V_{Z 1}=0,25 \cdot V_{C} \\
& V_{Z 2}=0,3 \cdot V_{C} \\
& V_{Z 3}=0,5 \cdot V_{C} \\
& V_{Z 4}=0,7 \cdot V_{C}
\end{aligned}
$$

Fig. 16 The composition of the breathing gas $x_{j}$ in the breathing bag of the $N x-S C R C R A B E$ apparatus as a function of $i$-fold flushing of the breathing loop with oxygen for different $V_{Z} / V_{C}$. Source: own study based on research results No: DOBR-BIO8/09/01/2016. 


\section{ConCluSions}

The directions of further research involve a continuation of performing measurements of the flushing process of the apparatus and maintaining a stable oxygen content in the breathing loop of the SCR CRABE. The verification of the permanent character of changes for the modified oxygen flushing process of the SCR CRABE should be carried out on the basis of the obtained experimental results $x_{j} \geq x_{j} \min \in[93,04 \div 95,39] \% v$ and further data exploration and analysis, evaluation of variability and the stability of the supervised process. A stable oxygen content in the breathing loop of the diving apparatus must ensure the maintenance of the vital functions of the diver's body under specific diving conditions and meet the critical requirements for the designed decompression due to the minimisation of risk related to the DCS threat. Decompression has been designed for system $\mathrm{II}^{42}$ nitrox dives according to NO-07A010 redundantly ${ }^{43}$, taking into account the redundancy resulting from the underestimation of minimum oxygen content in the breathing loop.

Bearing in mind the fact that the developed technology is designed for site diving, in conditions that take into account the underwater effort, the possibility of implementing additional safety systems should be considered, both in a simple form and in the form of systems equipped with sensory, expert ${ }^{44}$ and actuator 45 systems. In the breathing systems diving apparatuses, the implementation of such solutions serves as information on the current concentration or partial pressure of oxygen. It is important from the point of view of preventing hypoxia and risks resulting from the toxic effects of oxygen on the diver's body 46 during the stay at the bottom and during decompression. Diving technologies for military applications ${ }^{47}$ accept a higher level of risk for underwater activities 48 than, e.g., technologies designed for civilian or recreational diving. Therefore, for operational reasons, they may accept higher maximum partial pressure of oxygen and longer exposure times. Indicator systems, used to control the parameter, may inform the operator by means of a warning signal when the set oxygen concentration threshold is exceeded at each dive stage.

Process monitoring, from the point of view of the ability to minimise its variability, should be focused on measuring process values that would allow the control of flushing efficiency at the dive and decompression stages. A relatively small amount of effort is required to implement sensory analytical systems focused on process output parameters. It is possible to conduct online monitoring of the breathing space of the apparatus through the available specialised measurement systems. For reasons of safety ${ }^{49}$ of underwater mine operations, this should be considered, especially when diving at medium and deep depths. and with long dive times at the bottom. Prior to application, any protective sensory 50 systems should have their measurement systems assessed ${ }^{51}$ with regard to estimating the metrological properties and their stability against the process tolerance limits.

By publishing this paper I would like to thank the project manager, Prof. Ryszard KŁOS, PhD, of the Polish Naval Academy for the possibility of cooperation and participation in this project.

At the same time, I would like to express my gratitude to all the collaborators from the research group and in particular to Mr. Maciej KONARSKI, MD, who was responsible for the medical supervision and protection of the project, as well as to the manager of experimental diving Mr. Roman SZYMAŃSKI, whose work, commitment and professionalism in performing the research were an inspiration for writing this article.

\section{REFERENCES}

1. Official Journal of Laws of the Ministry of National Defence no. 6 item 44. Decision No. 75/MON of the Minister of National Defence of 1 April 2005. Instruction on introducing weapons and military equipment into the Armed Forces of the Republic of Poland and withdrawing weapons and equipment that do not meet the requirements of the army. Warsaw: MON, 2005;

2. AMP-15. Standards for Naval Mine Warfare Acoustic Measurements - STANAG $1097 / 1418 / 1431$. Brussels: NSO, 2013;

3. AODP-07 EOD. Equipment requirements and equipment - STANAG 2897. Brussels: NSO, 2007;

4. Instruction No. 106. of the Head of the Inspectorate for Armed Forces Support of 17 November 2010 in the case of introducing the CRABE Mixed Diving Camera to the Polish Armed Forces. no place: IWSZ, 2010

5. Kłos R.Konarski M.Szymański R. Woźniak A. Temporary guidelines for nitrox diving with the possibility of oxygen decompression for CRABE diving apparatus (INSTRUCTION ver. 4.11 - 12.05.2011). Gdynia: ZTPP AMW, 2011;

6. NO-07-A010. Diving for military purposes. Divingwith the use of nitrox Requirements. Warsaw: WCNJK, 2011;

7. R. Kłos. Decompression options for the CRABE diving apparatus. Gdynia: Polish Hyperbaric Medicine and Technology Society, 2011. ISBN 97883-924989-4-0;

8. Decompression options for the AMPHORA diving apparatus. Gdynia: Polish Hyperbaric Medicine and Technology Society, 2012. ISBN 978-83924989-8-8;

9. NO-07-A118. Diving for military purposes. Terminology and classification. Warsaw: WCNJK, 2015

10. NO-07-A057:2003. Diving for military purposes - Mine destruction by mine divers in mine operations. Warsaw: WCNJK, 2003;

11. R Kłos. Trimix decompression system for CRABE diving apparatus: Gdynia: Polish Hyperbaric Medicine and Technology Society, 2016. ISBN 978-83-938322-5-5;

12. Letter of intent between the Minister of National Defence of the Republic of Poland and the Minister of Defence of the French Republic concerning the strengthening of cooperation in the field of maritime operations. Warsaw: MON, 2013;

13. R. Kłos. Standard decompression. Temporary guidelines for Tx trimix decompression for CRABE diving apparatus. Gdynia: ZTPP AMW, 2018.

dr inż. Arkadiusz Woźniak

Katedra Technologii Prac Podwodnych

Akademia Marynarki Wojennej w Gdyni

ul. Smidowicza 69

81-103 Gdynia

tel. 261262746

ar.wozniak@amw.gdynia.pl 
1 SCR - semi - closed rebreather,

2 owing to a shortage of spare parts, high delivery costs, absence of emergency power kits, diving technology and the parameters of UiSW (Military Equipment and Armaments) which do not meet the expectations of the SZRP after joining NATO,

3 Instruction on introducing armaments and military equipment into the Armed Forces of the Republic of Poland and withdrawing armaments and equipment not meeting military requirements, Decision No 75/MON of the Minister of National Defence of 1 April 2005. (Journal of Laws of the Ministry of Defence No 6 , item 44 and of 2006 No 407, item 251),

${ }^{4}$ Recommendation No. 106 of the Chief of the Armed Forces Support Inspectorate of 17 November 2010,

${ }_{5}^{5}$ AMP-15 Standards for Naval Mine Warfare Acoustic Measurements - STANAG 1097 /1418/ 1431,

${ }^{6}$ AODP-07 EOD Equipment requirements and equipment - STANAG 2897,

7 similar to those developed earlier for apparatuses: FGT I/D, OXY-NG, AMPHORA, etc.

8 mine countermeasure, $M C M$,

${ }^{9}$ explosive ordinance disposal, EOD - detection, identification, on-site assessment, disarmament, recovery and destruction of munitions. It may also include explosive munitions that have become unsafe due to damage or deterioration,

10 regulations on the security of performance of underwater works in the Polish Armed Forces,

11 National Centre for Research and Development,

12 underwater mine operations - activities related to the underwater search, identification of any explosive or hazardous items, including their transfer to the surface or destruction by means of explosives, as well as their dismantling, neutralisation underwater or on the surface during diving and underwater works,

13 Implemented in years:2012 $\div 2015$,

${ }^{14}$ maximum operating depth, $\mathrm{MOD}=60 \mathrm{~m} \mathrm{H}_{2} \mathrm{O}$ - maximum operational depth expressed in metres of water column equivalent to the maximum pressure for which the diving system is designed,

15 resulting from the nitrox diving system I based on the use of EAD,

${ }^{16}$ context is understood here as the system environment, i.e. the supersystem for the breathing loop ventilation system of the diving apparatus,

17 in addition to monitoring other relevant diving parameters,

18 resulting from the adopted decompression assumptions,

19 in this case - oxygen,

20 CNS - Central Nervous System,

21 in this case the nitrox mix,

22 in terms of the number of cycles and repetitions performed,

${ }^{23}$ for the decompression schedule,

${ }^{24 *}$ rebreather flushing procedures:

1. Crabe AQUALUNG Nice 2010 diving procedures.

2. Diving Technology of the French Navy La Cellule Plongée Humaine et Intervention Sous la Mer (CEPHISMER).

3. Kłos R. Konarski M. 2011. Temporary guidelines for nitrox diving with oxygen decompression possibility for CRABE rebreather (MANUAL ver. 4.11-12.05.2011). Gdynia : ZTPP AMW, 2011.

4. Kłos R. 2011. Decompression selection options for the CRABE rebreather. Gdynia 2011: Decompression selection options for the CRABE rebreather. Gdynia 2011: Polish Hyperbaric Medicine and Technology Society: ISBN 978-83-924989-4-0.

5. Kłos R. Trimix decompression system for the CRABE rebreather: Gdynia 2016: Decompression selection options for the CRABE rebreather. Gdynia 2011: Polish Hyperbaric Medicine and Technology Society: ISBN 978-83-938322-5-5.

${ }^{25} \mathrm{XBS}$ - External Breathing System

$2632,5 \% v \mathrm{O}_{2}$,

27 showing each stage of apparatus flushing,

$2840 \% v_{2} \mathrm{O}_{2}$,

29 the so-called primers,

${ }^{30}$ outliers,

31 LCL-ang. Lower Control Level,

32 which can also be revealed by means of control charts after selecting the appropriate distribution, e.g. the Weibull distribution,

33 the higher the oxygen content in the decompression phase, the more effective the process of desaturation of inert gases from a diver's body,

${ }^{34}$ short and long term,

35 before changing the procedure

36 modification of the apparatus flushing procedure,

${ }^{37}$ stability and alignment relative to the nominal value

38 after the identification and modification of only one parameter,

39 after the identification and modification of only one parameter

40 e.g. limiting the number of procedures for flushing the breathing loop of the apparatus while at the bottom, in order to minimize the acoustic signal for the duration of the task

${ }^{41} \mathrm{CTQ}$ - ang. Critical to Quality,

42 this is a system based on a fixed nitrox mixture composition corresponding to the maximum diving depth. For this system, decompression tables are developed with the corresponding nitrox composition,

43 in excess,

${ }^{44}$ e.g. the use of a computer system which emulates the human decision making process,

45 operational components

46 oxygen pulmonary and cerebral toxicity

${ }^{47}$ technologies for military applications presuppose the existence of an effective supervision over the selection of and training of divers, e.g. MCM/EOD. In addition, they take into account the basic guidelines for the qualification, preparation and keeping those divers in proper shape, for whom the diving technology is intended,

48 engineering, rescuing, combat or mine operations,

49 Regulation of the Minister of National Defence of 21 June 2012 regarding safety of underwater works in the organisational units subordinate to or supervised

by the Minister of National Defence (JL No. 1, it. 810 as amended),

50 if not performed already,

${ }^{51} M S A$ - measurement system analysis. 